\title{
Determination of reproductive maturity in the female nine-banded armadillo (Dasypus novemcinctus) $\S$
}

\author{
R. D. Peppler*†, F. E. Hossler* and S. C. Stone $\ddagger$ \\ Departments of * Anatomy and $\dagger$ Obstetrics and Gynecology, Quillen-Dishner College of Medicine, \\ East Tennessee State University, Johnson City, TN 37614, U.S.A. and $\ddagger$ Department of Gynecology \\ and Obstetrics, University of California, Irvine Medical Center, Orange, CA 92668, U.S.A.
}

\begin{abstract}
Summary. At 3-month intervals from birth to 27 months of age, 3 female armadillos were killed. The number and size of follicles $>202 \mu \mathrm{m}$ were determined, plasma progesterone concentration was measured, and values were correlated with age. Blood samples were taken monthly by femoral vein puncture and plasma was analysed by radioimmunoassay for progesterone concentration. At necropsy, both ovaries were visually inspected for a corpus luteum, weighed and then processed for routine histology. The number of normal, antral follicles $>202 \mu \mathrm{m}$ were counted. These follicles were arbitrarily categorized into 15 different size groups (every $77 \mu \mathrm{m}$ ). Total number of follicles $>202 \mu \mathrm{m}$ varied from $15.5 \pm 1.3$ at 15 months of age to $26.3 \pm 1.9$ at 21 months. Follicles of a size ( $>978 \mu \mathrm{m})$ most likely to ovulate were present only at $\geqslant 9$ months of age. Progesterone values remained below the adult concentration $(5 \mathrm{ng} / \mathrm{ml})$ until 15 months of age. A concentration of progesterone indicative of ovulation $(\sim 10 \mathrm{ng} / \mathrm{ml})$ occurred between 17 and 20 months of age. The findings of the present study demonstrate that the female armadillo is reproductively mature after 15 months of age.
\end{abstract}

\section{Introduction}

The nine-banded armadillo (Dasypus novemcinctus) is a desirable animal model for biomedical research, especially reproductive biology, because of certain characteristics: life-span of 12-15 years, body weight of $4-5 \mathrm{~kg}$, low body temperature $\left(30-35^{\circ} \mathrm{C}\right)$ and monozygous, quadruple offspring. Most of the knowledge about reproductive characteristics of the female armadillo has originated from the investigations of Newman (1912), Hamlett (1932, 1935), Talmage \& Buchanan (1954), Enders (1966), Nakakura, Czekala, Lasley \& Benirschke (1982), Peppler \& Stone (1976, 1980a, b), Peppler (1979) and Peppler \& Canale (1980).

The purpose of the present study was to determine at what age female armadillos are reproductively mature. This was done by measuring the number and size of follicles at 3-month intervals from birth to 27 months of age, and determining the plasma progesterone concentration monthly.

\section{Materials and Methods}

Mature female armadillos were captured from the wild in southeast Louisiana during the months of August through February. They were maintained in groups of 2, 3 or 4 in pens $(1.2 \times 1.2 \mathrm{~m})$ under conditions of controlled lighting (fluorescent illumination 07:00-16:00 h) and temperature $\left(25 \pm 1^{\circ} \mathrm{C}\right)$. These animals were anaesthetized with ketamine hydrochloride $(20 \mathrm{mg} / \mathrm{kg}$ body weight, intramuscularly) and $2-3 \mathrm{ml}$ blood were taken from the superficial femoral vein into a

§ Reprint requests to: Dr R. D. Peppler, College of Medicine, UJCHS, 800 Madison Avenue, Memphis, TN 38163 , U.S.A. 
syringe containing heparin. Progesterone concentrations in the plasma were measured by radioimmunoassay as described previously (Thorneycroft \& Stone, 1972; Peppler \& Stone, 1976, 1980a). Progesterone values $20 \mathrm{ng} / \mathrm{ml}$ or higher indicated that the animals were pregnant (Peppler \& Stone, 1976). This was verified by palpation. Subsequently, these pregnant animals were isolated into individual pens until parturition in March or April.

After parturition, the young were kept with their mothers for $\sim 2$ months, weaned and then penned with 5-6 others of the same sex (but not necessarily from the same litter). Each month, 5 of these female animals were anaesthetized and a blood sample was obtained from the superficial femoral vein as previously described. The blood was kept in an ice bath and centrifuged under refrigeration, and the plasma removed and frozen at $-20^{\circ} \mathrm{C}$ until assayed.

At 3-month intervals from birth to 27 months of age (except at age 24 months), 3 female armadillos were killed. Ovaries were inspected visually for a corpus luteum (CL) and the presence or absence of a CL was later confirmed microscopically. The ovaries were fixed in Bouin's solution, embedded in paraffin wax, sectioned serially at $5 \mu \mathrm{m}$ and stained with haematoxylin and eosin. Each section was examined with the identity of individual ovaries remaining unknown until all were studied. Follicular size was calculated by measuring two diameters at right angles to each other in the section containing the oocyte nucleolus. Normal follicles $>202 \mu \mathrm{m}$ in diameter were counted and categorized arbitrarily into 15 different size groups (Table 1). Both ovaries from each animal were examined and the resulting value (total no. of follicles per animal) was halved to obtain a value per ovary.

Statistical significance was determined by Student's $t$ test for paired means and $P<0.05$ was considered significant.

\section{Results}

At birth, numerous primordial follicles, but no secondary follicles, were apparent in the ovary (Fig. 1a). By 3 months of age, secondary follicles had appeared. The number of these follicles demonstrate a progressive pattern of follicular development (more larger-sized follicles) with age (Table 1) but little change in the total number of follicles larger than $>202 \mu \mathrm{m}$. Only between 12 and 15 , and 15 and 18 months of age did a difference in the total number of follicles occur. Such a finding may be caused by atresia of some follicles near the time of ovulation. Follicles $(>978 \mu \mathrm{m})$ likely to ovulate (Peppler \& Canale, 1980) were present in some of the ovaries at 9 months of age and continued to appear until 27 months (the last time point examined). Even when these large follicles $(>978 \mu \mathrm{m})$ were present, nests of primordial follicles were still found (especially at 9,12 , 15 and 18 months of age) in the ovaries (Fig. lb). At 15 months of age, a corpus luteum (CL) was present in one ovary in 2 of the 3 animals killed (Fig. 1c). A CL was also present in ovaries of all animals killed at 18 and 21 months of age, and in 2 of the 3 animals killed at 27 months of age.

Plasma progesterone concentrations remained below the adult concentration of $5 \mathrm{ng} / \mathrm{ml}$ (Peppler \& Stone, 1980a) until 12 months of age (Fig. 2). A progesterone concentration $(\sim 10 \mathrm{ng} / \mathrm{ml})$ indicative of the presence of a viable corpus luteum (Peppler \& Stone, 1980a) did not occur until 17-20 months of age.

\section{Discussion}

An account of the growth and maturation of an individual follicle in the armadillo was given by Newman (1912). The armadillo spontaneously ovulates one egg (Newman, 1912; Hamlett, 1932) once a year (Talmage \& Buchanan, 1954) about the middle of July (Hamlett, 1932, 1935), with the subsequent formation of a single corpus luteum (Newman, 1912; Hamlett, 1932). Maturation of all but one follicle in both ovaries ceases before ovulation and atresia of the arrested follicles occurs (Newman, 1912). 


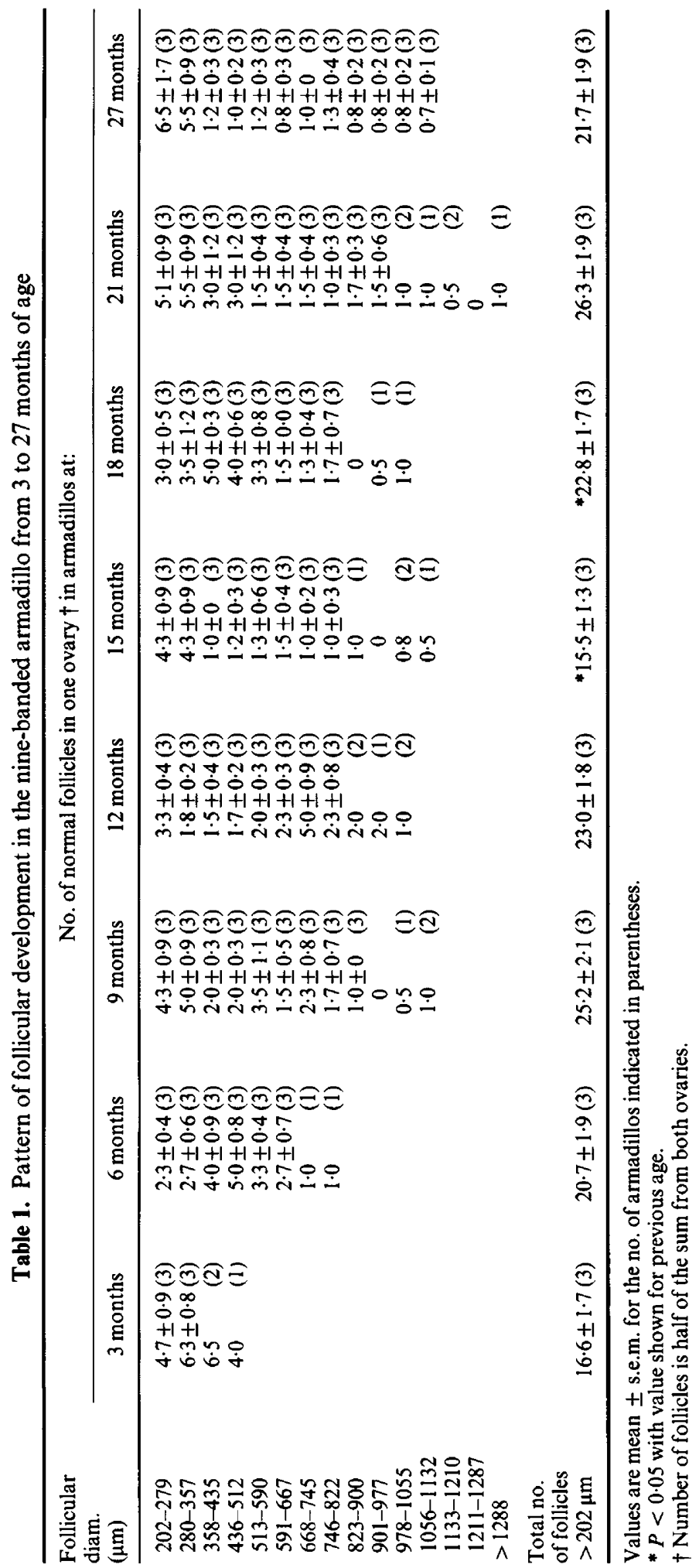



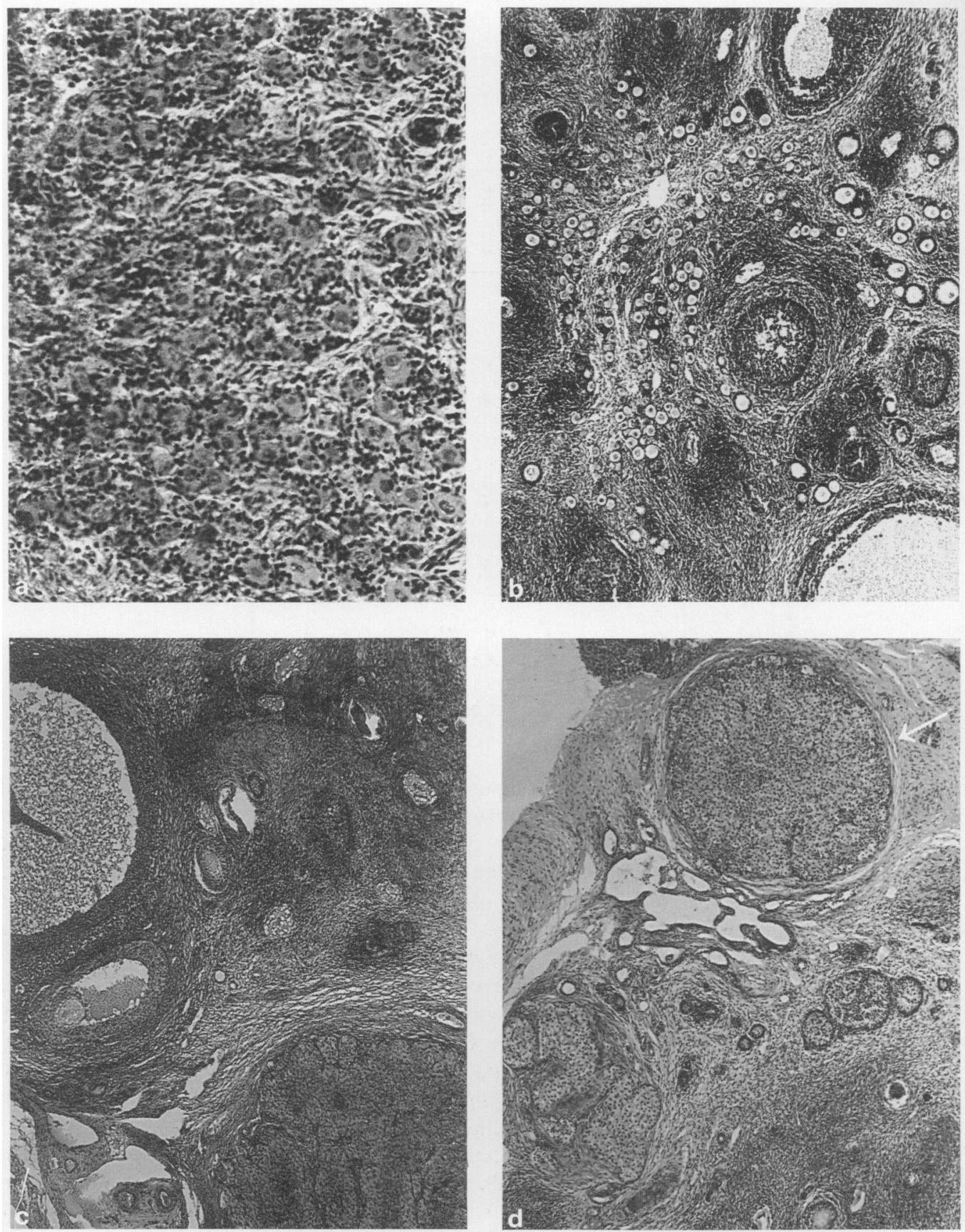

Fig. 1. Ovaries of armadillos at different ages. (a) At birth; numerous primordial follicles, but no secondary follicles are present. $\times 30$. (b) At 12 months of age; large follicles $(978 \mu \mathrm{m})$ are present but nests of primordial follicles are also evident. $\times 12$. (c) At 15 months of age: a corpus luteum is present lower right. $\times 12$. (d) At 18 months of age; a corpus luteum is present lower left corner and accessory adrenal tissue is arrowed. $\times 12$. 


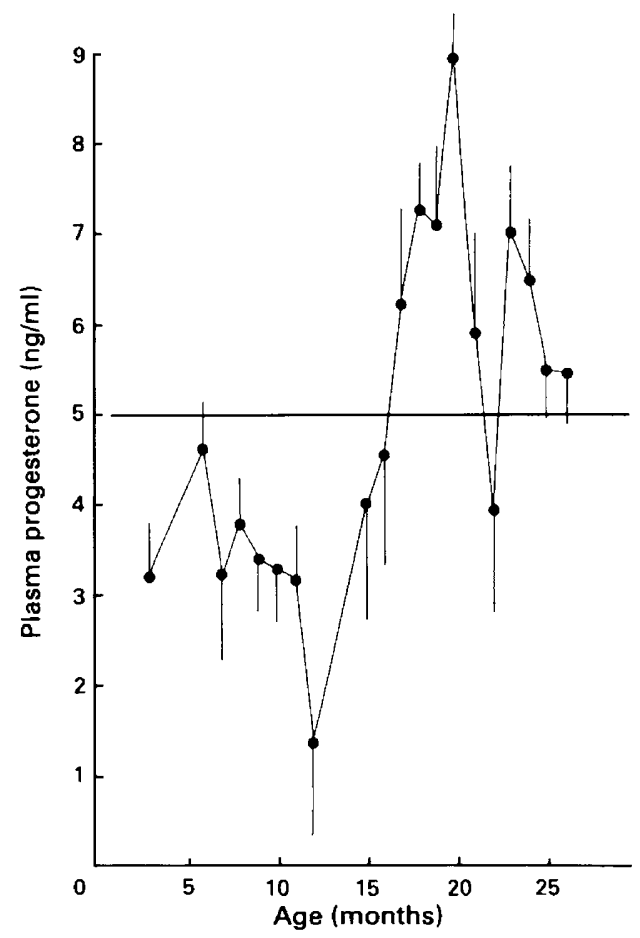

Fig. 2. Plasma progesterone concentrations (mean \pm s.e.m.) in female armadillos from 3 to 27 months of age. Each value represents an average of the analysis of at least 5 samples except those at $25-27$ months of age when $n=3$. The baseline value for adult armadillos is $5 \mathrm{ng} / \mathrm{ml}$.

The annual pattern of follicular development in the armadillo has been described (Peppler $\&$ Canale, 1980). The total number of follicles $>358 \mu \mathrm{m}$ in diameter remains constant from January until June but is $50 \%$ less during the remaining months of the year except in October and November. More follicles $>978 \mu \mathrm{m}$ in diameter (those most likely to ovulate) are present in ovaries (2.7-4.1 follicles/ovary) in the months of April, May, June and October than during any of the other months when values vary from zero (December) to 1.6 (March). The number and size of follicles measured in the present study can be compared to follicular data from a previous study (Peppler \& Canale, 1980), when the numerical time points in the present study (i.e. the 3-month blocks) are related to specific months of the year and when the two smaller size groups (202-279 and $280-357 \mu \mathrm{m}$ ) are eliminated. Since the armadillos in this study were born in late March or early April, 3, 15 and 27 months of age equate to the month of July. Four adult animals had $6.2 \pm 1.3$ follicles $>358 \mu \mathrm{m}$ per ovary in July (Peppler \& Canale, 1980). In the present study, armadillos killed in July at 3,15 and 27 months of age had 5.2 $\pm 0.9,8 \cdot 2 \pm 1 \cdot 3$ and $8.9 \pm 1 \cdot 4$ follicles $>358 \mu \mathrm{m}$ per ovary respectively. In October, 6 adult armadillos had $23.2 \pm 1.9$ follicles $>358 \mu \mathrm{m}$ per ovary (Peppler \& Canale, 1980), while in the present study, armadillos at 6 and 18 months of age had $15.7 \pm 0.8$ and $17.3 \pm 1.7$ such follicles per ovary, respectively. This finding of fewer follicles at 6 months of age can be attributed to the immature status of the armadillo at this age. In January, 6 adult armadillos had $12.8 \pm 1.9$ follicles $>358 \mu \mathrm{m}$ per ovary (Peppler \& Canale, 1980), and in the present study, armadillos killed at 9 and 21 months of age had $15.9 \pm 0.9$ and $15.7 \pm 0.9$ such follicles per ovary, respectively.

Measurements of seasonal progesterone concentrations in peripheral plasma (Peppler, 1979) when correlated with the presence of a $C L$ demonstrated that concentrations of $10 \mathrm{ng} / \mathrm{ml}$ were indicative of ovulation. In the present study, concentrations approached this value between 17 and 
20 months of age. Such data indicate that the female armadillo does not ovulate until after 15 months of age. The circulating progesterone concentration before 15 months of age is probably produced by the adrenals and ovarian structures not of luteal origin. Nakakura et al. (1982) have suggested that captive female armadillos have a high progesterone concentration attributable to adrenal production. In the current study, values were not of the magnitude reported by Nakakura et al. (1982) and could be due to the fact that the animals in the present study were born in captivity and not subjected to the environmental change of being taken from the wild. Variability in progesterone concentration could be the result of the physiological differences in individual CL and, in some instances, accessory adrenal tissue (Fig. 1d). Further experimentation is needed to clarify the exact contribution of all of these sources to the total progesterone concentration in peripheral plasma of the female armadillo.

In the present study, follicles did not attain the size necessary for ovulation until 9 months of age and it was only at 15 months that all animals killed at any particular time had at least one of these larger-sized follicles in their ovaries. None of the animals killed before 15 months of age had a CL. Furthermore, progesterone concentrations $(\sim 10 \mathrm{ng} / \mathrm{ml})$ indicative of ovulation did not occur until 17-20 months of age. Collectively, these findings indicate that the armadillo does not ovulate until at least 15 months of age.

This work was supported by Grant No. AI 11204 from the National Institutes of Health, U.S.A. We thank J. Canale and S. Hemelt for technical help and C. Canter and P. Briselden for secretarial assistance.

\section{References}

Enders, A.C. (1966) The reproductive cycle of the nine-banded armadillo (Dasypus novemcinctus). Symp. zool. Soc. Lond. 15, 295-310.

Hamlett, G.W.D. (1932) The reproductive cycle in the armadillo. Z. wiss. Zool. 141, 143-157.

Hamlett, G.W.D. (1935) Delayed implantation and discontinuous development in the mammals. $Q$. Rev. Biol. 10, 432-447.

Nakakura, K., Czekala, N.M., Lasley, B.L. \& Benirschke, K. (1982) Fetal-maternal gradients of steroid hormones in the nine-banded armadillo (Dasypus novemcinctus). J. Reprod. Fert. 66, 635-643.

Newman, H.H. (1912) The ovum of the nine-banded armadillo: growth of the ovocytes, maturation and fertilization. Biol. Bull. mar. biol. Lab., Woods Hole 23, $100-140$.

Peppler, R.D. (1979) Reproductive parameters in the nine-banded armadillo. Anat. Rec. 193, 649-650.

Peppler, R.D. \& Canale, J. (1980) Quantitative investigation of the annual pattern of follicular development in the nine-banded armadillo (Dasypus novemcinctus). J. Reprod. Fert. 59, 193-197.
Peppler, R.D. \& Stone, S.C. (1976) Plasma progesterone level in the female armadillo during delayed implantation and gestation: preliminary report. Lab. Anim. Sci. 26, 501-504.

Peppler, R.D. \& Stone, S.C. (1980a) Plasma progesterone level during delayed implantation, gestation and the postpartum period in the female armadillo. Lab. Anim. Sci. 20, 188-191.

Peppler, R.D. \& Stone, S.C. (1980b) Clomipheneinduced ovulation in the 9-banded armadillo (Dasypus novemcinctus). Lab. Anim. 14, 329-330.

Talmage, R.V. \& Buchanan, G.D. (1954) The armadillo. A review of its natural history, ecology, anatomy and reproductive physiology. The Rice Institute Pamphlet 41, 1-135.

Thorneycroft, I.H. \& Stone, S.C. (1972) Radioimmunoassay of serum progesterone in women receiving oral contraceptive steroids. Contraception 5, $129-146$. 